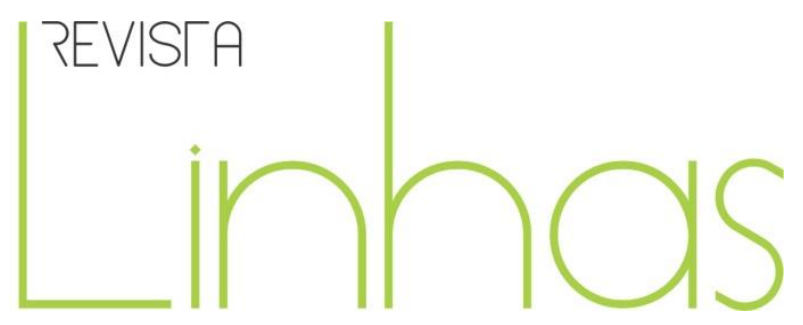

\title{
Trajetórias de vida e formação de professores indígenas nos estados do Tocantins e Amazonas
}

\section{Resumo}

O artigo em questão resulta das reflexões advindas de nossas experiências em cursos de formação inicial e continuada de professores indígenas, na área do ensino de Matemática, nos Estados do Tocantins e Amazonas. As ações de ensino desenvolvidas nestes cursos, desde os anos de 2006, tiveram como objetivo compartilhar as trajetórias pessoais e profissionais dos indígenas, uma vez que esses professores pertencem a distintos povos, tanto linguisticamente, como quanto aos seus entendimentos sobre educação familiar e escolar. Para tanto, recorremos às narrativas registradas durante os cursos de formação que permitiram investigar os saberes e fazeres tradicionais dos indígenas como estratégias para o ensino e análise das aprendizagens dos professores que ensinam Matemática em contextos de interculturalidade e intraculturalidade no intuito de buscar identificar e discutir quais as conexões entre os saberes tradicionais e os conhecimentos escolares. $O$ diálogo entre essas duas formas de conhecimento deu-se por meio das rodas de conversas que se configuraram como entrevistas narrativas contribuindo para a investigação sobre o ser (professor indígena), além de permitir conhecer melhor os "parentes" em seus processos formativos; de registrar o não registrado; dando voz aos silenciados evidenciando os diferentes modos de conceber a aprendizagem nas diversas culturas. Os aportes teóricos adotados, referentes ao uso da Pesquisa Narrativa, advêm de Clandinin e Connelly (2011), Jovchelovitch e Bauer (2008), Aragão (2011) e Gonçalves (2011). No que tange ao ensino de Matemática, no contexto cultural indígena, assumimos as ideias de D’Ambrosio (2002) em seu Programa Etnomatemática.

Palavras-chaves: Professores indígenas; Escolas indígenas; Matemática - estudo e ensino.

\section{Gerson Ribeiro Bacury}

Doutorando em Ciências e Matemáticas pela Universidade Federal do Pará - UFPA - Brasil gersonbacury@gmail.com

\section{Elisângela Aparecida Pereira de Melo}

Doutoranda em Ciências e Matemáticas pela Universidade Federal do Pará - UFPA - Brasil elisangelamelo@uft.edu.br

\section{Tadeu Oliver Gonçalves}

Doutor em Educação Matemática pela Universidade Estadual de Campinas - UNICAMP - Brasil tadeuoliver@yahoo.com.br

\section{Para citar este artigo:}

BACURY, Gerson Ribeiro; MELO, Elisângela Aparecida Pereira de; GONÇALVES, Tadeu Oliver. Trajetórias de vida e formação de professores indígenas nos estados do Tocantins e Amazonas Revista Linhas. Florianópolis, v. 16, n. 32, p. 172 - 199, set./dez. 2015. 


\title{
This work consists of reflections on our experiences in the degree programs for initial and continuing education of indigenous teacher in mathematics in Tocantins and Amazonas States, Brazil
}

\begin{abstract}
Since these teachers belong to distinct peoples with different understandings related to family-based and school-based education, not to mention linguistic differences, the teaching actions developed in these programs have sought, from 2006 onward, to share the professional and personal trajectories of these indigenous teachers. Drawing upon narratives recorded during the degree programs, we investigate the traditional knowledge and practices of indigenous teachers as strategies for teaching and the analysis of teacher education. This permits us to identify and discuss what the connections are between traditional, indigenous knowledge and school-based knowledge among indigenous teachers who teach mathematics in intercultural and intracultural contexts. The dialogue between these two forms of knowledge occurred through round tables that were configured to permit narrative interviews that would contribute to our understand of their being (indigenous teachers). This allows us to better know the "relatives" of this being in its formative process, to register the unregistered, to give voice to the silenced, and to exhibit different conceptions of learning in diverse cultures. The adopted theoretical contributions related to the use of narrative research include Clandinin and Connelly (2011), Jovchelovitch and Bauer (2008), Aragão (2011), and Gonçalves (2011). With regards to the teaching of mathematics in an indigenous cultural context, we adopt D'Ambrosio's (2012) ideas from their EthnoMathematics Program.
\end{abstract}

Keywords: Indigenous teachers; Indian schools; Mathematics - study and teaching. 


\section{Situando a pesquisa no tempo e espaço}

Falar em educação escolar indígena é estar atento para uma modalidade de ensino que foi introduzida nas comunidades indígenas devido ao processo de contato desses povos com o não indígena. Assim, existe um processo educativo que funciona no seio dessas comunidades, como estratégias de produção e difusão de conhecimentos que se dá de forma holística, em sintonia com suas cosmovisões de mundo, práticas sociais que poderiam ser valorizadas e dialogadas no ambiente escolar, para dar sentido ao ensino de Matemática e às outras disciplinas do currículo escolar, valorizando ainda suas produções dos saberes tradicionais e evidenciando, dessa forma, os distintos conhecimentos como uma construção humana inerente a todo grupo sociocultural.

O dialogar com o saber e fazer oriundos de suas práticas sociais, nas quais podemos identificar elementos no intuito de estabelecer relações com o conhecimento escolar matemático, difundido nas escolas e universidades é o grande desafio de uma Educação Matemática comprometida com a construção da cidadania e inserção dos povos indígenas no amplo contexto brasileiro. Partindo do pressuposto que os povos indígenas investigados possuem diferentes modos de viver, costumes, tradições e modos de situar-se no espaço territorial de vivência cotidiana.

Neste aspecto também pautados em nossas experiências de formadores de professores indígenas e no compartilhar dessas experiências com o nosso orientador, Prof. Dr. Tadeu Oliver Gonçalves, muitas questões sobre a formação de professores que ensinam matemática, foram levantadas, a saber: Em que termos educativos os indígenas se constituíram professores? Em que sentido formativo a parceria com a universidade tem contribuído para o exercício da docência na perspectiva interdisciplinar e intercultural?

Assim, apresentamos na primeira seção, intitulada "Os indígenas das regiões do Tocantins e Autazes/AM: seus espaços territoriais", um recorte acerca da localização espaço-geográfica dos povos Karajá, Karajá de Xambioá, Javaé, Krahô, Krahô-Kanela, Xerente e Apinayé, Guaraní, Funiô, Pakararu, Tuxá e Ava-Canoeiro, no Estado do Tocantins e o povo Mura do município de Autazes no Estado do Amazonas, destacando alguns traços das manifestações culturais, sociais, históricas e políticas destes povos. 
$\mathrm{Na}$ segunda seção, intitulada "Os indígenas das regiões do Tocantins e Autazes/AM nos espaços formativos", abordaremos os cursos de formação de professores indígenas, desde o curso de Formação Inicial em Magistério Indígena, como é o caso dos povos do Tocantins com o Curso de Licenciatura Específica Mura e do Curso de Licenciatura “Formação de Professores Indígenas” no Estado do Amazonas.

Na terceira seção, intitulada "Histórias de Vida e Formação dos Professores Indígenas", analisaremos à luz da narrativa as falas desses professores buscando compreender os distintos papéis a que eles foram submetidos no decorrer da implantação da Escola em suas aldeias, aos processos de políticas públicas de formação do indígena professor.

Destacamos que estamos nos dedicando, há alguns anos, a estudar e pesquisar a formação de professores em áreas de contexto de diversidade sociocultural, em especial a indígena, nos Estados do Tocantins e Amazonas, na área da Matemática. Ressaltando orientações para o processo de ensino e aprendizagem nesse contexto que carece um pouco mais de atenção, tendo em vista a riqueza dos saberes e fazeres tradicionais que emergem como fonte de investigação, tanto para a proposição de propostas de formação de professores quanto para a mobilização de atividades investigativas tanto em âmbito escolar, como na própria comunidade.

Neste percurso formativo, pontos importantes foram sendo acrescidos e fortificados na nossa discussão, como a formação inicial do professor indígena, mais precisamente suas relações estabelecidas para o ensino de Matemática, isto é, nos preocupamos em compreender quais são os conteúdos matemáticos que devem ser ensinados para que os professores indígenas possam articulá-los com suas práticas socioculturais em sala de aula.

Desse modo, fomos estabelecendo diálogos, laços de amizades e confiança que nos conduziram a conhecer o ser indígena professor em suas ambiências de formação e de vivência diária. Esses momentos de interação, de trocas de experiências e de confidências mútuas, os quais interpretamos no campo dos pressupostos metodológicos da pesquisa como uma narrativa, a qual: 
[...] significa compreendê-las na perspectiva das experiências e dos processos significativos de formação e do desenvolvimento de professores, considerando as múltiplas vozes, que contam e interpretam. [...] pesquisar histórias de formação não significa entende-las de maneira linear e sem dificuldades. Pelo contrário, trata-se de tarefa complexa. Embora o propósito não seja o de destacar a negatividade da vida e dos processos de formação vividos pelos sujeitos investigados, com todos os percalços presentes no processo, certamente, o que o sujeito não refere, ao rememorar e relatar suas histórias, parece não ter tido significado para a sua história pessoal e profissional. (GONÇALVES, 2001, p. 72)

Nesse sentido, buscamos compreender por meio das experiências desses professores indígenas, seus percursos de histórias e formação, juntamente com nossa vivência nesse rico contexto, uma interação entre os conhecimentos indígenas e não indígenas, visto que tanto eles (pertencentes a várias etnias) quanto nós (pesquisadores desse objeto de estudo) em nossas diferenças linguísticas, socioculturais e de conhecimento matemático, convergimos para uma ressignificação na ação escolar e docente.

\section{Os indígenas das regiões do Tocantins e Autazes/AM: seus espaços territoriais}

$\mathrm{Na}$ perspectiva de situarmos os sujeitos deste estudo, o fazemos a partir dos espaços territoriais de vivência cotidiana que ocorrem no espaço local (própria aldeia) e/ou em espaço global (outras aldeias, universidades, espaços sociais e de políticas indigenistas, entre outros). É nesses contextos que ocorrem as relações intraculturais e interculturais (D'AMBROSIO, 2004), responsáveis pela geração de novos conhecimentos.

Assim, são os povos indígenas dos Estados do Tocantins e Amazonas que interagem entre si de modo a fortalecer as tradições socioculturais, as organizações e políticas internas, entre outras que são intrínsecas à dinâmica de auto formação e constituição destes povos. 


\section{O Estado do Tocantins}

Apresenta uma população de aproximadamente 11.000 indígenas ${ }^{1}$, com perspectiva de crescimento populacional. Esses povos têm uma cultura que pode ser expressa por meio de diferentes manifestações, bem como uma história de luta e de sobrevivência que os faz manter com vitalidade seus saberes tradicionais, mantendo-os ligados aos seus antepassados por meio da renovação e agregação desses saberes aos conhecimentos que estão sendo adquiridos em contato direto com os não indígenas.

Neste contexto de diversidade étnica destacaremos os povos indígenas do referido estado e sua localização geográfica, conforme a Figura 01, que conta de professores indígenas, oriundos de sete povos, a saber: Karajá (Ilha do Banal - Lagoa da Confusão), Karajá-Xambioá (Santa Fé), Javaé (Ilha do Bananal - Formoso do Araguaia e Lagoa da Confusão), Krahô (Itacajá e Goiatins), Krahô-Kanela (Lagoa da Confusão), Xerente (Tocantinía) e Apinayé (Tocantinopólis). Incluem-se ainda os povos: Guaraní, que vivem entre os Karajá de Xambioá; os Funiô com os Apinayé; os povos Pakararu, Tuxá e Ava-Canoeiro entre os Javaé. A presença desses indígenas entre os citados anteriormente é resultado em parte, de casamentos interétnicos.

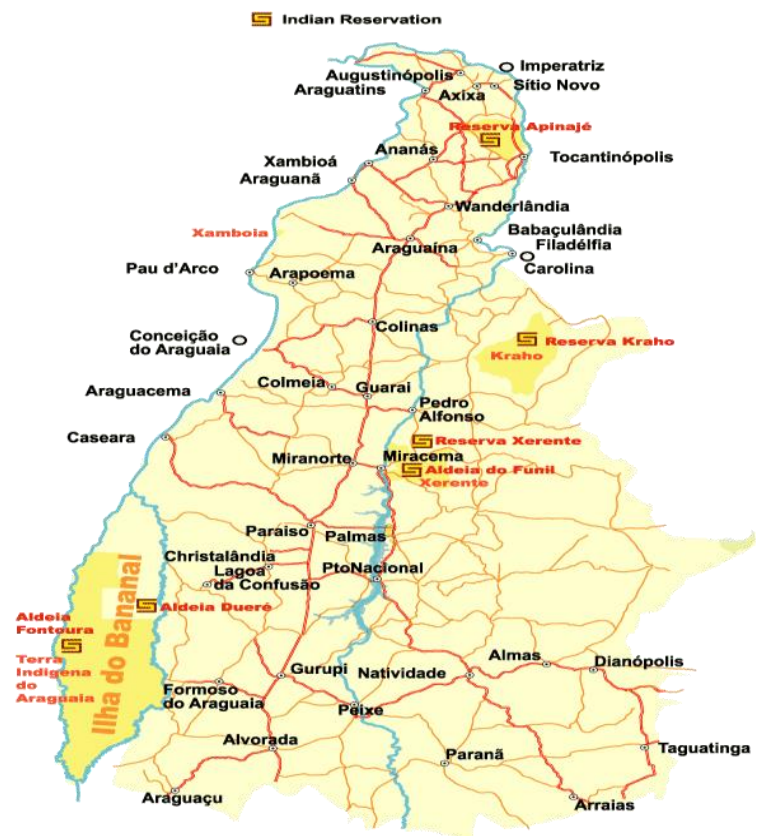

Figura 01- Mapa das Terras Indígenas Tocantinenses Fonte: http://www.palmas.org/indians/tocmapindios.gif

\footnotetext{
${ }^{1}$ Vede: http://indigenas.ibge.gov.br/graficos-e-tabelas-2
} 
De modo a caracterizar os povos supracitados no espaço-tempo de suas histórias de vidas e de constituição, autoafirmação sociocultural e linguística, sendo os mesmos reconhecidos nos distintos espaços de convívios, sejam eles os internos ou os externos às suas aldeias, verificamos que:

A interação entre indivíduos também encontra, [...], um grande potencial, ainda difícil de se aquilatar, de gerar ações comum. Nota-se em alguns casos o predomínio de uma forma sobre a outra e mesmo a supressão e a eliminação total de alguma forma, mas na maioria dos casos o resultado é a geração de novas formas culturais, identificadas com a modernidade. Ainda dominadas pelas tensões emocionais, as relações entre indivíduos de uma mesma cultura (intraculturais) e, sobretudo, as relações entre indivíduos de culturas distintas (interculturais) representam o potencial criativo da espécie. Assim como a biodiversidade representa o caminho para o surgimento de novas espécies, na diversidade cultural reside o potencial criativo da humanidade. (D'AMBROSIO, 2004, p. 42)

Assim, os Karajá, os Karajá de Xambioá e os Javaé formam um único povo - o Iny, pertencentes linguisticamente ao Tronco Macro-Jê, família Karajá. São considerados povos das águas. Residem às margens do rio Araguaia e têm sua subsistência proveniente da coleta de frutos, de peixes e de outros alimentos próprios de sua cadeia alimentar.

As expressões das tradições se dão de várias formas, nas pinturas corporais, nas confecções de artesanatos, em especial os de barro, como por exemplo, as bonecas ritxóó (tombadas como patrimônio cultural pelo Instituto do Patrimônio Histórico e Artístico Nacional - IPHAN), nas artes plumárias dos raheto (cocares), nos rituais de danças e de ritos de passagens, como o Hetohoky.

Os Xerente que também se autodenominam Akwẽ, residem nas terras indígenas Xerente e Funil, são pertencentes linguisticamente ao Tronco Macro-Jê e família Jê. São organizados socialmente por meio dos partidos ou metades clânicas Doĩ e Wahirẽ. Considerados povos da floresta e grandes guerreiros e corredores.

Têm sua subsistência advinda da coleta de frutos, caça, pesca e das roças de 
vazantes e tocos. Das suas tradições culturais dá-se destaque para a festa do Daĩsipẽ, em que ocorre a tradicional corrida da tora grande, nominação masculina e feminina.

Os Krahô e Krahô-Kanela denominam a si próprios de mẽhĩ, e a língua falada por estes povos pertencem à família linguística Jê, tronco Macro-Jê. Suas aldeias são circulares, com pátio central, conforme Figura 02.

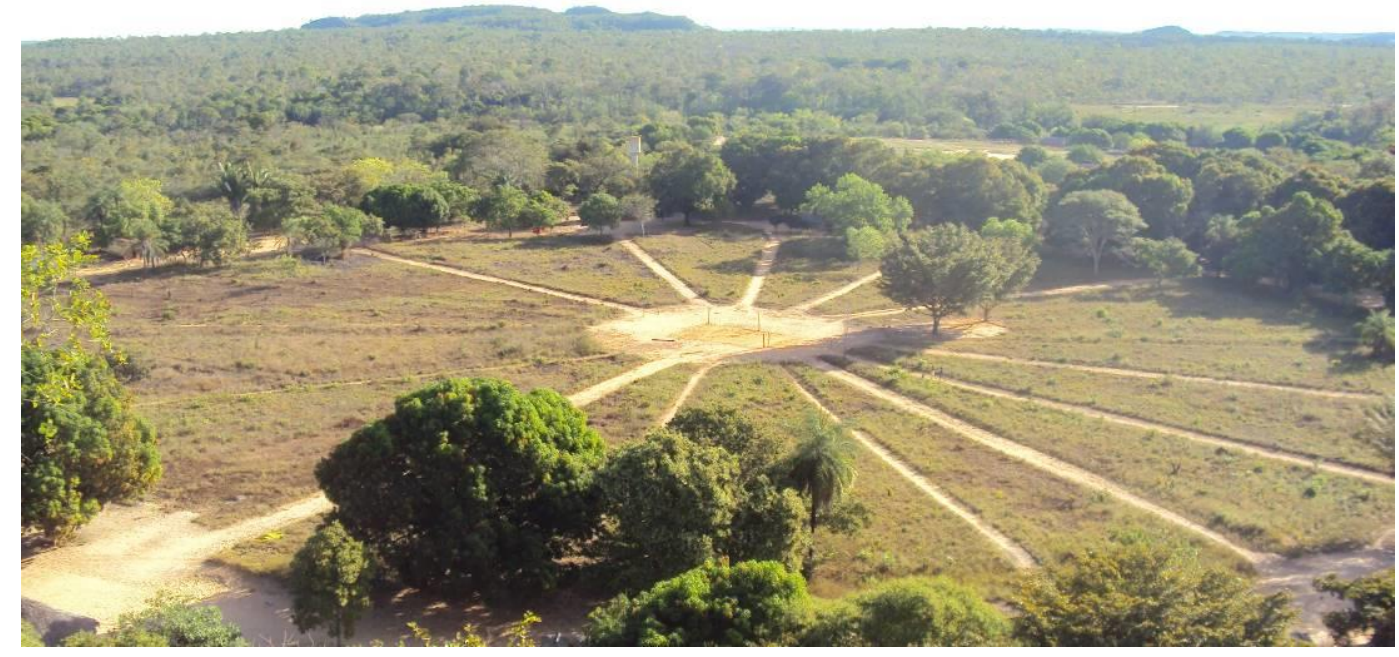

Figura 02 - Vista do Pátio Central da aldeia Krahô Fonte: Elisangela Melo

A organização social e política dos mẽhĩ divide-se em dois grandes partidos ou metades: wakmẽye (partido do verão) e katãmye (partido do inverno). Das tradições desse povo, destacamos a festa do jàt jõpiin 'Festa da Batata', tep mẽ tere 'Peixe e Lontra', e os ritos de iniciação Pempcahàc e Ketwajê.

O povo Apinayé ou Pahi, pertence à família linguística Jê, tronco Macro-Jê, são bilíngues e mantêm com vitalidade seus saberes tradicionais. Os Apinayé são organizados socialmente pelo dualismo, ou seja, por duas metades cerimônias Kooti e Koore que se complementam entre si, tendo o sol e a lua como elementos de criação desse povo. 
É o quinto mais populoso da microrregião de Manaus. Essa microrregião se destaca pela produção de leite e por sediar a maior festa bovina da Amazônia Ocidental a Festa do Leite. Os estudos de Pinto (2011) destacam que essa região, até meados do século XVIII era habitada apenas pelo povo Mura, conhecidos nesta região por sua resistência ao colonizador português. O nome Autazes tem origem nos rios Autaz-Açu e Autaz-Mirim que cortam suas terras. A economia do município é proveniente da criação de gado leiteiro, dando à Autazes o título da cidade do leite e queijo.

Esse município, conforme Figura 03, está localizado a aproximadamente 118 km, em linha reta, da cidade de Manaus / AM, possuindo uma área de 7.599,363 km², sendo o acesso somente por via fluvial ou terrestre.

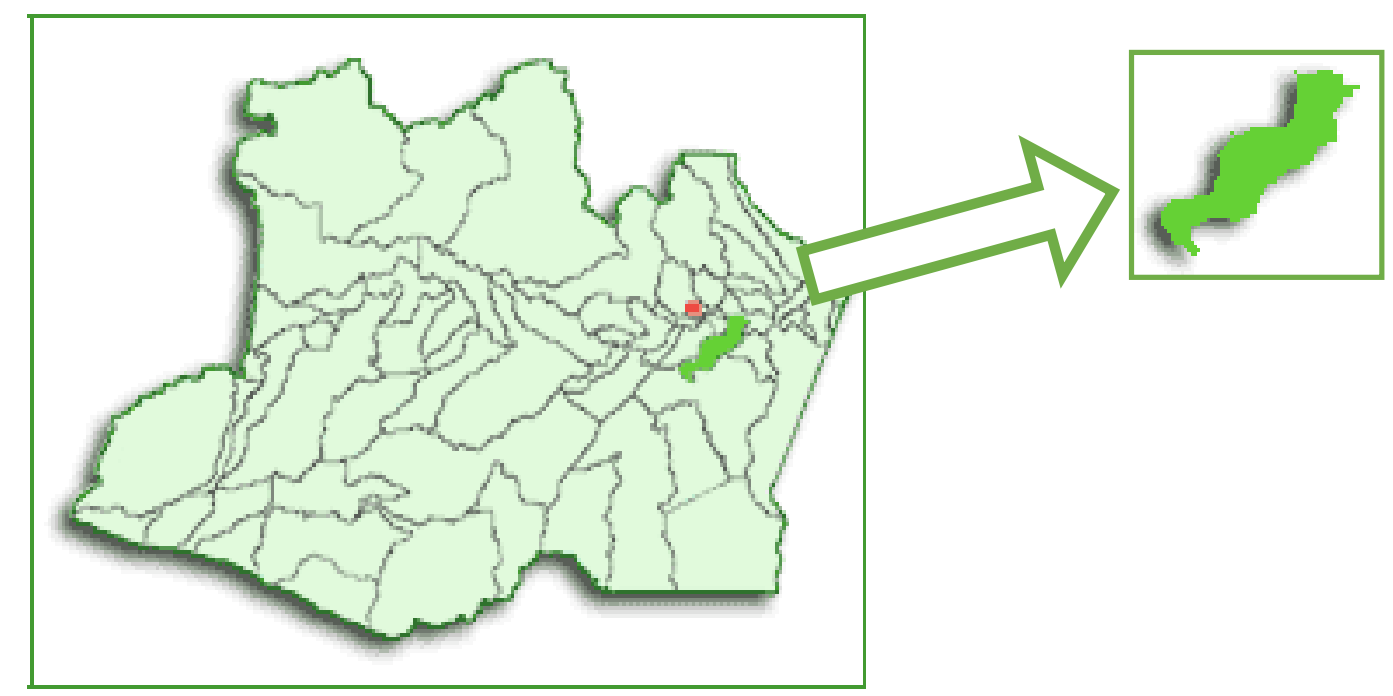

Figura 03- Município de Autazes Fonte: http://www.manausonline.com/images/mapa_autazes.gif

Nessa região histórica do município de Autazes está concentrado o povo Mura, com uma população estimada em 6.877 habitantes ${ }^{2}$; ao longo de seus rios e lagos, situamse onze aldeias indígenas: Capivara, Cuia, Gapenú, Igarapé-Açú, Jabuti, Jauari, Josefa, Murutinga, Paracuúba, São Félix e Trincheira. Reportaremo-nos às aldeias Cuia, Josefa, Murutinga, São Félix e Trincheira, pois nelas residem os sujeitos de nossa investigação os universitários indígenas que assumem nas escolas da aldeia, a docência.

\footnotetext{
${ }^{2}$ Vede: http://indigenas.ibge.gov.br/graficos-e-tabelas-2
} 
Para entendimento e compreensão acerca das dificuldades de acesso às aldeias, apresentaremos um pequeno panorama geográfico de situação e locação tomando como base as ilustrações desses locais pelos próprios indígenas.

A aldeia Cuia, ver Figura 04, situa-se à margem direita do rio Paraná de Cuia e seu acesso é por via fluvial ou terrestre. Nesse último, ao sair pelo ramal que dá acesso à comunidade indígena São Félix seguindo pela BR 319, ainda na rodovia AM 254, após 10 minutos, chegamos ao destino.

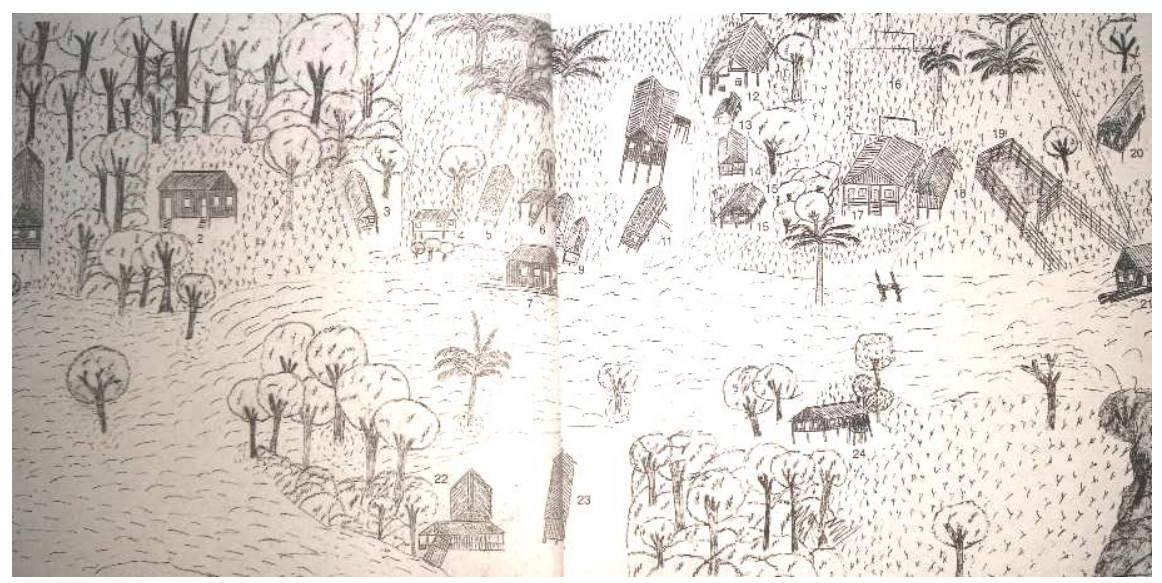

Figura 04 - Aldeia Cuia

Fonte: Silva (2008, p. 60-61)

A aldeia Josefa, ver Figura 05, está localizada em um dos lagos que compõem o Rio Madeira. Os estudos de Pinto (2011) apontam uma curiosidade quanto à origem do nome dessa aldeia. De acordo com o que dizem os professores indígenas da comunidade, o nome "Josefa" tem sua origem em dois fatos: primeiro, devido à morte de dois padres, que por muito tempo, habitaram as terras onde se situa a aldeia; um chamado José e o outro Sampaio. Segundo, pela presença de uma antiga moradora, a índia chamada Josefa que permaneceu na aldeia após a morte dos dois padres.

Para chegar até a aldeia Josefa, é necessário partir da sede do município de Autazes. Este percurso é realizado inteiramente por estrada de chão de barro e pouco linear, possui um acesso difícil que dura aproximadamente 30 minutos. 


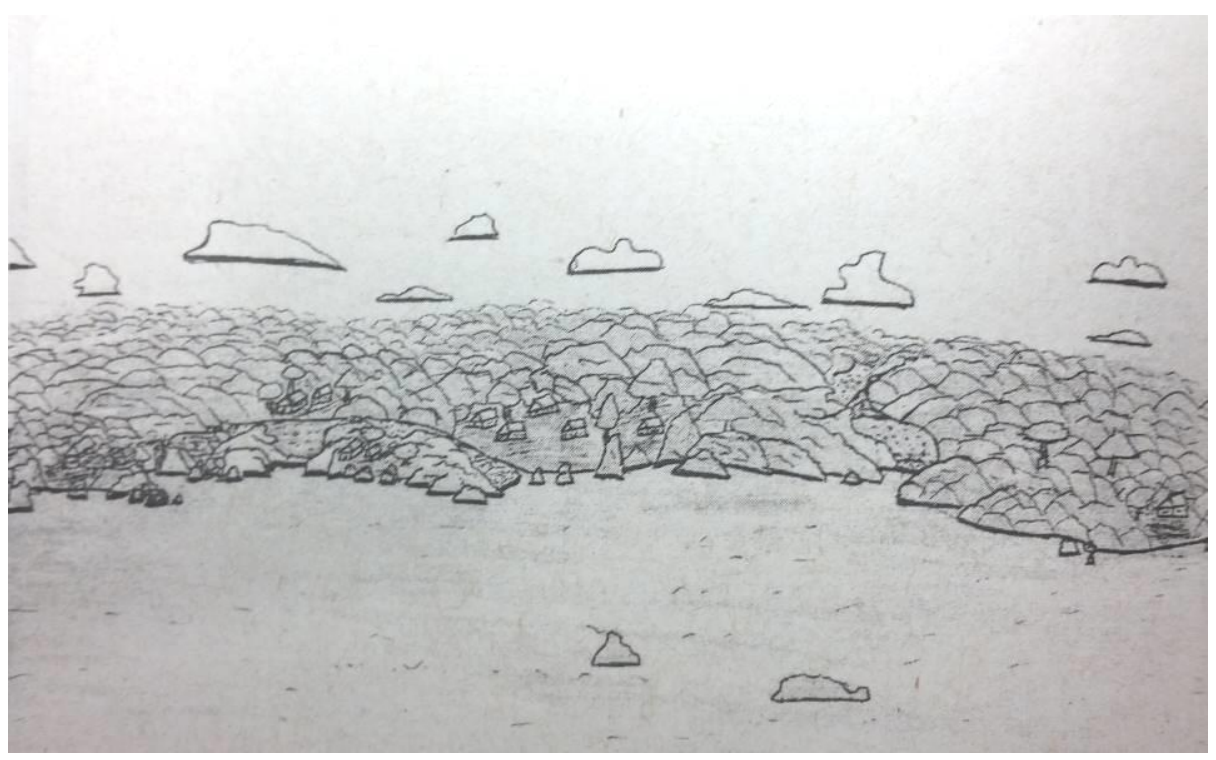

Figura 05 - Aldeia Josefa antigamente Fonte: Silva (2008, p. 168)

A aldeia Murutinga, ver Figura 06, está localizada à margem direita do Lago Murutinga. O acesso à esta localidade é somente via fluvial, com duração de 15 a 20 minutos. Entretanto, na época das cheias dos rios, esse tempo aumenta para 45 minutos devido ao fato de se utilizar outra rota, mais longa e sinuosa.

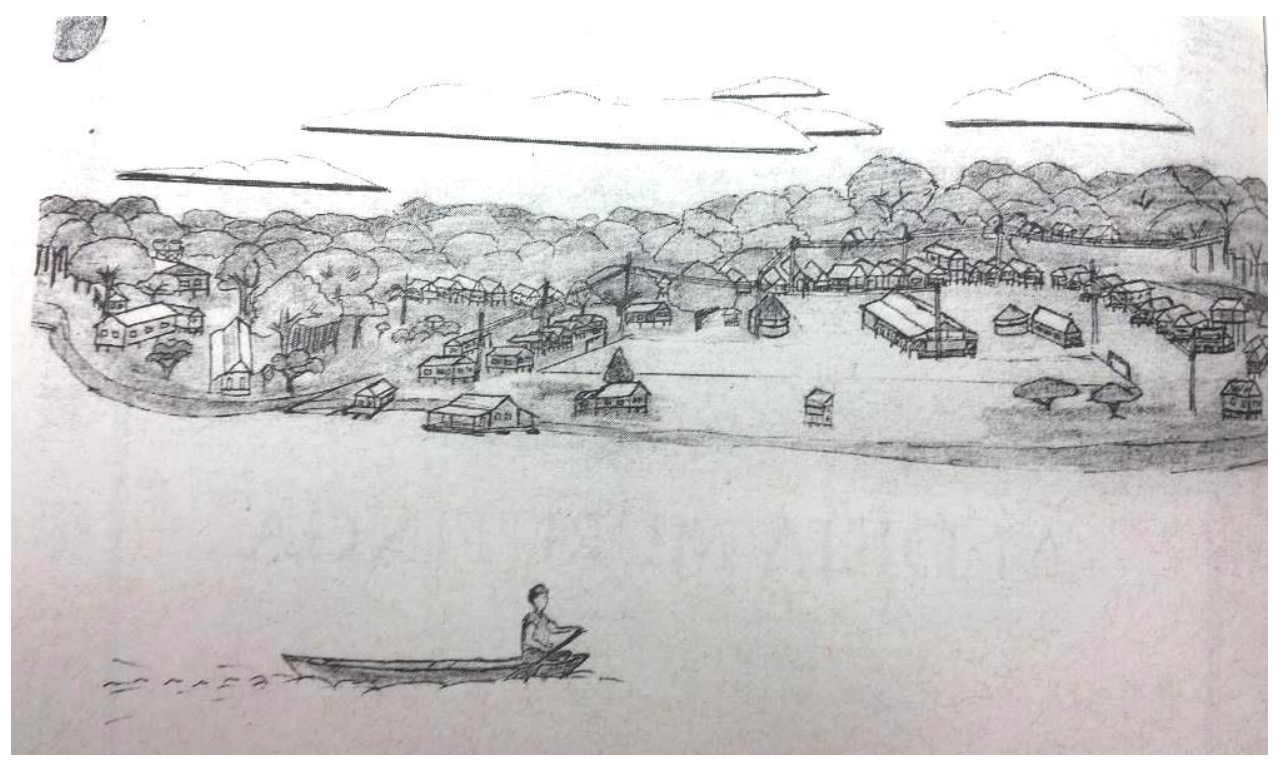

Figura 06 - Aldeia Murutinga

Fonte: Silva (2008, p. 220) 
Na aldeia São Félix, ver Figura 07, o acesso mais utilizado é por via fluvial. Esta localidade encontra-se à margem esquerda do rio Paraná e do rio Autaz-Açu. Dista 8 km, em linha reta, do município de Autazes; dependendo do tipo de embarcação, esse trajeto pode durar de 8 minutos até 1 hora. Entretanto, os estudos de Pinto (2011) sinalizam que há a outra alternativa de acesso, via terrestre, através de um ramal localizado próximo do fim da estrada BR 319 - AM 254.

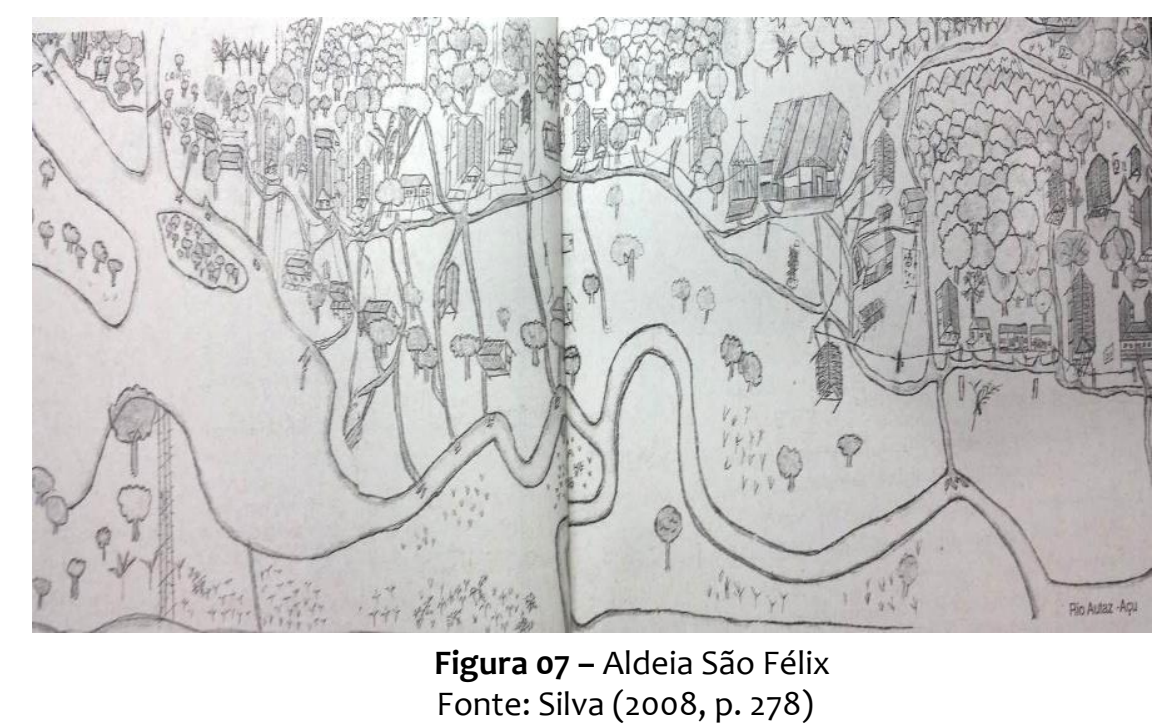

Por fim, a aldeia Trincheira, que está localizada à margem esquerda do lago com o mesmo nome, situado no rio Preto do Pantaleão. O percurso é somente por via fluvial e dura cerca de 30 minutos partindo do município de Autazes. Podemos constatar nos estudos de Silva (2008) que o nome que deu origem à aldeia está relacionado com as táticas de guerra, ver Figura 08, oriundas de uma revolta popular chamada Cabanagem, ocorrida entre os anos de 1835 e 1840 na província do Grão-Pará (atual estado do Pará). Essa revolta possuía uma característica marcante: grande parte dos revoltosos era formada por pessoas pobres que moravam em cabanas nas beiras dos rios da região, chamados cabanos. 


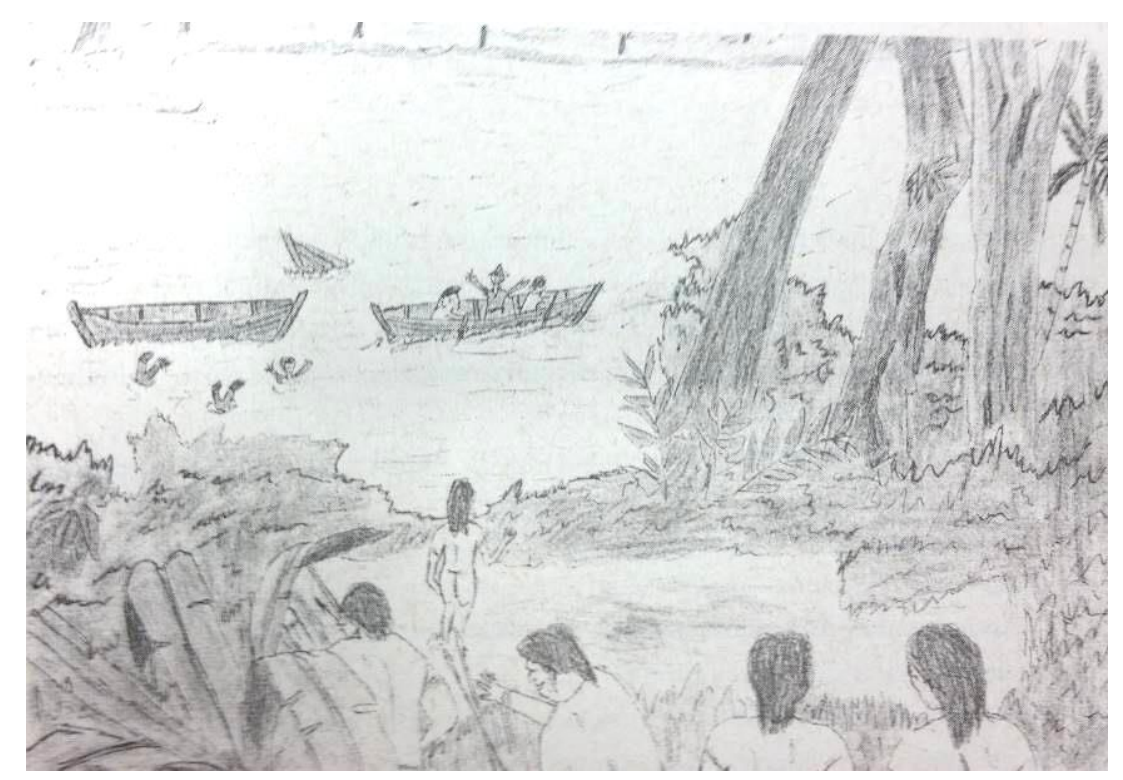

Figura 08 - Ataque aos barcos invasores

Fonte: Silva (2008, p. 335)

De modo geral, esses povos mesmo estando em diferentes espaços físicos de vivência, de interação, de convivência e de formação, são detentores de grande pluralidade que vai além da diversidade étnica e cultural, para uma convivência humanizada, em que cada povo sociocultural pode dar a sua parcela de contribuição para a construção de um país com igualdade e respeito entre todos.

\section{Os indígenas do estado do Tocantins e região de Autazes/AM em seus espaços formativos}

Reportaremo-nos, em um primeiro momento, à formação dos professores indígenas do Estado do Tocantins, que se inicia com o Curso de Magistério Indígena, sendo este uma ação formativa de responsabilidade social e política da Secretaria Estadual de Educação do Estado do Tocantins (SEDUC), cujo objetivo é formar o indígena professor para atuar nas séries iniciais da Educação Básica.

No segundo momento, abordaremos a licenciatura específica para a formação de professores indígenas nas instituições de nível superior, mais precisamente o Curso de Licenciatura "Formação de Professores Indígenas" desenvolvido pela Faculdade de Educação da Universidade Federal do Amazonas - UFAM, com o objetivo de formar, em 
nível superior, na perspectiva intercultural e interdisciplinar, professores Mura para atuarem na segunda etapa do Ensino Fundamental e Ensino Médio nas escolas de suas aldeias.

O Curso de Magistério Indígena no estado do Tocantins

Ocorre nos meses de janeiro e julho (períodos estes de férias dos professores), desde sua implantação nos anos de 1990 aos anos atuais. A realização do curso ocorre em diferentes cidades do estado, de modo que os professores possam estar mais próximos de suas comunidades. Mas nos últimos três anos, por uma questão de logística, está sendo ofertado aos professores no município de Miracema. Durante o curso, as disciplinas são ofertadas de forma modular, de forma que os professores indígenas (aqui, na condição de estudantes) possam cursá-las sem prejuízo de carga-horária.

Nossa atuação no Curso de Magistério Indígena ocorre como formadora na área do Ensino de Matemática, buscando efetivar um ensino e aprendizagem aliados as vivências dos professores em sala, considerando suas experiências, anseios, necessidades e dificuldades em relação à didática, em especial no que tange ao uso das práticas socioculturais indígenas e o conteúdo da Matemática escolar. Tal caracterização se dá pelo fato de que os professores indígenas almejam em suas práticas educativas o congregar dos saberes tradicionais em sala de aula.

Nessa perspectiva, adentramos o contexto indígena tocantinense e autaziense, com a intenção de conhecer e vivenciar as práticas socioculturais que ali são desenvolvidas, sob a luz da teoria de D’Ambrosio (2002), ao problematizar a ação pedagógica - por meio do seu Programa Etnomatemática - no que tange à formação do indígena professor a partir de suas necessidades didáticas e pedagógicas. Tal programa enfatiza ser necessário voltar o olhar para a constituição e concepção do saber indígena no seu próprio contexto de aldeamento e as vias do fazer da sala de aula da escola indígena, haja vista que: 
[...] é extremamente importante reconhecer que os povos indígenas mantêm vivas as formas de educação tradicional, que podem contribuir na formação de uma política e prática educacional adequada, capaz de atender aos anseios, interesses e necessidades diárias da realidade hoje. [...] onde a relação entre os conhecimentos tradicionais e os novos conhecimentos poderão se articular de forma equilibrada. (SILVA, 2002, p. $113-114)$

Por isso, é importante que todo formador em seu planejamento respeite os desejos e anseios dos indígenas no que concerne a sua formação inicial e continuada, em particular os seus espaços e tempos; estes sim, têm sido um dos principais objetivos que temos buscado ao longo dos anos de atuação no Curso de Magistério Indígena e de formação continuada dos professores indígenas, considerando que "cada povo tem uma cultura, cada povo tem uma língua. Da mesma maneira, cada povo tem a sua matemática” (GERDES, 2007, p. 159), as quais são retratadas nas aulas de matemática como atividades investigativas pelos professores em formação, podendo as mesmas serem projetadas para a sala de aula.

Neste sentido, nos reportamos às aulas de Matemática que ocorrem no Curso de Magistério Indígena, planejadas a partir da realidade sociocultural de cada povo envolvido, das particularidades e especificidades das línguas, das organizações sociais e comunitárias, dos modos de sustentabilidade, entre outros artefatos próprios da cultura, face aos conteúdos da Matemática escolar.

Assim, as metodologias adotadas foram direcionadas à participação de todos, de tal modo que os grupos constituídos para a realização dessas atividades propostas tivessem sempre um ou mais professores pertencentes a povos diferentes para que pudessem trocar experiências e interagir entre si, favorecendo a interculturalidade e intraculturalidade.

Dentre os conteúdos discutidos em sala de aula com os professores, temos primado pela ideia de número e suas necessidades em ampliar esse conceito de modo a contribuir com suas práticas cotidianas, comerciais e práticas referentes à geometria, isto é, para uma visão mais ampla de conhecimentos que vai desde a construção de uma casa até as pinturas corporais. 
Certamente o debate entre os saberes oriundos das práticas tradicionais indígenas e os conhecimentos matemáticos escolares são abordados conjuntamente com os professores por meio da proposta pedagógica da Etnomatemática que permeia o fazer da sala de aula, em que os professores são os sujeitos de sua formação, uma vez que esta proposta tem como objetivo:

[...] fazer da matemática algo vivo, lidando com situações reais no tempo [agora] e no espaço [aqui]. E, através da crítica, questionar o aqui e agora. Ao fazer isso, mergulhamos nas raízes culturais e praticamos dinâmica cultural. Estamos, efetivamente, reconhecendo na educação [matemática] a importância das várias culturas e tradições na formação de uma nova civilização, transcultural e transdisciplinar. (D'AMBROSIO, 2002, p. 46)

Nesta perspectiva intencionamos, por meio de atividades investigativas, instigar a prática matemática local com base nos saberes e fazeres imbricados nas culturas desses professores indígenas. Portanto, entendemos que o essencial no desdobramento que se inicia desde a formação inicial indo até a formação em nível superior desses professores, ocorre por meio de processos mobilizados no coletivo e no contexto da aldeia.

O Curso de Licenciatura "Formação de Professores Indígenas" na UFAM

Tem seu início a partir do ano de 2005, por meio de articulação entre a Secretaria de Ensino Superior - SESu e a Secretaria de Educação Continuada, Alfabetização e Diversidade - SECAD, o Ministério de Educação - MEC lançou o Edital do Programa de Apoio à Formação Superior e Licenciaturas Indígenas - Prolind, com a possibilidade de financiamento para as Instituições de Ensino Superior Públicas. Os estudos de Silva; Horta (2010) revelam que a UFAM - a partir da solicitação da Organização dos Professores Indígenas Mura - OPIM, região de Autazes - participou desse edital. Sendo aprovada a criação do curso que inicialmente se chamou Curso de Licenciatura Específico para os 
professores indígena Mura. O Projeto Político Pedagógico do referido curso foi construído com a participação da comunidade indígena interessada.

Esse processo participativo foi realizado em três momentos. O primeiro momento foi dedicado ao Diagnóstico da realidade escolar Mura a partir do levantamento de dados existentes e, posteriormente, sua complementação referente à demanda para a segunda etapa do Ensino Fundamental e Médio. Esses dados complementares foram oriundos das viagens às aldeias com a participação de professores da OPIM, visitando cerca de 15 comunidades Mura da região de Autazes/AM. A sistematização, análise e apresentação desses dados foi realizada nas dependências da UFAM, com a participação de seus docentes envolvidos no projeto e também do povo Mura.

O segundo momento, referente à Definição de uma Política Linguística, visto que “[...] por razões históricas, ligadas à violência do contato o povo Mura deixou de falar a língua Mura [...]” (SILVA; HORTA, 2010, p. 191). Para os Mura, a proposta deste curso viabiliza, entre outros, a possibilidade de revitalização do fortalecimento de sua identidade e sua valorização juntamente com outros povos, assim como na sociedade não indígena.

Uma das reivindicações da OPIM junto à Comissão de elaboração do Projeto Político Pedagógico foi a garantia do ensino da língua indígena - com destaque à escolha do Nheengatu - para os professores Mura participantes do curso de licenciatura. Tal exigência foi justificada pela OPIM devido ao fato, em tempos passados, do povo Mura ter tido sua língua materna praticamente extinta. Assim, o ensino da língua Nheengatu ficou sob a responsabilidade pedagógica e didática da OPIM.

Por fim, a Definição de critérios para ingresso no curso, que estabeleceu o número máximo de 60 vagas, não havendo uma prova escrita, mas sim alguns critérios de seleção elaborados pela OPIM e adotados pela UFAM com destaque: ser índio Mura, ter Ensino Médio completo e comprovado e, ter as documentações pessoais básicas. A partir dos estudos de Silva; Horta (2010), destacamos dentro desse processo quatro situações interessantes: na primeira, o candidato não é professor atuante; nesse caso, a condição é que ele seja bem relacionado com a escola e comunidade, e ainda, deve ser indicado via ata de registro com a anuência da OPIM, da Organização dos Estudantes Indígenas Mura 
- OIEM e Setor de Educação Escolar Mura da Secretaria Municipal de Educação de Autazes.

Na segunda situação, caso a aldeia não tivesse candidato poderia ser indicado um indígena de outra aldeia, entretanto este candidato deveria passar por uma avaliação junto à OPIM.

Na terceira, o candidato é professor atuante nas aldeias e, deveria apresentar no ato da inscrição uma carta de autorização dada pela (s) liderança (s) de sua aldeia assim como da OPIM. Por fim, o candidato é professor em escola fora das aldeias, e deveria apresentar uma carta da autorização da OPIM para realizar sua inscrição no processo.

A perspectiva do ensino superior para os Mura vai além de ter um diploma, ou seja, eles buscam a valorização de sua própria cultura e modo de vida, a formação de indígenas preparados para enfrentar o mundo moderno e que essa formação possibilite uma qualificação crítica respeitando seus costumes, suas tradições e o modo de vida em suas aldeias.

Desde seu início, em 2008, o curso é desenvolvido pela Faculdade de Educação da UFAM, com duração de cinco anos, realizado de forma presencial, em módulos condensados, com 3.165 horas e a oferta de 60 vagas por turma. O curso está estruturado para atender os indígenas com habilitação nas áreas de Ciências Humanas e Sociais; Ciências Exatas e Biológicas; Letras e Artes.

É composto por três etapas: na primeira, caracterizada por uma formação geral que ocorre em dois anos com carga horária de 1.320 horas. Nessa etapa de formação, todos os alunos indígenas estudam juntos. Na segunda etapa, ocorre a formação específica, também com duração de dois anos e carga horária de 840 horas, de acordo com a opção de cada discente. Por fim, a etapa de integração das áreas, com duração de um ano, na qual todos os discentes indígenas discutem os resultados dos trabalhos de pesquisas, estágios, Projeto Político-Pedagógico das escolas indígenas, Trabalhos de Conclusão de Curso e outras questões relativas à formação diferenciada.

Nossa atuação no referido curso vem ocorrendo desde junho de 2010, ministrando a disciplina Matemática II, vivenciando experiências que desde então ressignificaram nossa visão sobre interculturalidade e interdisciplinaridade. Para Paula (1999), a 
interculturalidade é intrinsicamente ligada ao conhecimento. Nesse sentido, pudemos construir um novo conhecimento matemático a partir do contato com os indígenas e sua cultura como nos assegura Scandiuzzi (2009), na medida em que se conhece a Matemática de um grupo social culturalmente identificável, ele passa a fazer parte de nós, sendo seus costumes e hábitos respeitados, não necessitando de uma reeducação.

Assim, no enfrentamento ao desafio da interculturalidade junto ao conhecimento matemático dos indígenas, procuramos apresentar a diversidade de conhecimentos matemáticos como no caso das ideias de número, modos de contagem, entre outros, no intuito de estabelecer uma relação entre a Matemática e a cultura Mura.

Outro ponto abordado em nossa experiência com os indígenas é pautado na interdisciplinaridade na perspectiva formativa de transpor as barreiras que individualizam as disciplinas de Matemática, mais precisamente em uma mudança de postura no intuito de pensar o conhecimento matemático em sua totalidade, a partir das vivências dos discentes Mura e seus conhecimentos próprios de Matemática, Química, Física, Engenharia, Geografia, entre outros, ou seja, “[...] Diria que o sentido do interdisciplinar está na contribuição das áreas do conhecimento, no entendimento de um objeto de estudo comum, desvelando as várias dimensões que o envolvem, dando um sentido de totalidade" (STUANI, 2010, p. 78).

Nesta perspectiva, pensamos a elaboração de um conhecimento matemático junto aos indígenas de modo a compreender as diferentes maneiras de classificar, medir, inferir, ordenar, contar etc.

Para tanto, destacamos o Programa Etnomatemática, instituído por D’Ambrosio (2002), o qual busca o conhecimento contextualizado em diferentes grupos de interesse, povos e nações. Portanto, entendemos que a partir dos pressupostos da Etnomatemática, a Matemática com seu tecnicismo racional constitui-se também como um produto cultural no qual cada povo com sua cultura desenvolve sua própria Matemática.

Em outra compreensão, Mendes (1993) sinaliza que o termo "etno" indica também grupos como as sociedades indígenas que possuem maneiras de raciocínio e inferências próprias, a partir de uma educação diferenciada que contempla as seguintes 
características: seu próprio processo de educação, um currículo e material didático em conformidade com a sua realidade e o horário de estudo de acordo com sua escolha.

Neste contexto vem acontecendo nossa experiência com o ensino de Matemática aos indígenas, que se inicia com o povo Mura, em 2008, e hoje abrange outros povos que habitam o estado do Amazonas e adjacências, pois com o passar dos anos, o Projeto Político Pedagógico que inicialmente fora elaborado com vista a atender demandas do povo Mura, posteriormente, sofreu reformulações e adequações - como a mudança no nome do Curso, que passou a se chamar Curso de Licenciatura "Formação de Professores Indígenas" - de modo a atender novas demandas para o ingresso no ensino superior indígena, como foi o caso das turmas Munduruku e Sateré-Mawé, iniciadas em 2011 e as turmas do Médio Solimões, iniciadas em 2013. Atualmente, quatro novas turmas estão em processo de discussão e planejamento, a saber: Duas iniciadas no primeiro semestre de 2015 - turma do Alto Solimões e Turma de São Gabriel da Cachoeira. As demais - turma de Manicoré e Lábrea, ainda em processo de discussão e implementação.

\section{Histórias de vidas dos professores indígenas}

As histórias de formação e de constituição dos indígenas como profissionais da educação se confundem com a própria história de vida do ser indígena. Assim, para que possamos melhor compreender essa história, é necessário situarmos em linhas gerais os distintos processos educativos a que as populações indígenas foram submetidas por longos anos até a autonomia e gestão dos processos de formação, de ensino e aprendizagem, serem assumidos ainda que, em parte, pelos próprios indígenas.

Assim, reportamo-nos ao contexto das políticas públicas para a educação escolar indígena que aponta o longo percurso que os povos indígenas percorreram para a construção dos ideários à consolidação da escola em ambiente próprio, que viessem a valorizar a cultura tradicional, propiciando uma formação intercultural com vista ao exercício de uma formação ampla, igualitária, social e de cidadania, pautada no respeito às diferenças sociolinguísticas. 
Todavia, em um primeiro momento, a escola indígena não foi assumida pelos povos indígenas e, sim por outros segmentos da sociedade não indígena, como as missões religiosas: católicas e protestantes, Serviço de Proteção ao Índio - SPI, organizações indigenistas, Fundação Nacional de Apoio ao Índio - FUNAI, Secretarias Municipais e Estaduais de Educação. A educação escolar que foi propagada e disseminada em longas décadas por estes segmentos que tinham como objetivo pedagógico “domesticar" os povos indígenas com vistas à assimilação da cultura envolvente e integrá-los nesse contexto, de tal modo a:

[...] fazê-lo abdicar de sua língua, de suas crenças e de seus padrões culturais e incorporar, assimilar os valores e comportamentos, inclusive linguísticos, da sociedade nacional. [...] Porque o que se acreditava é que os costumes e crenças indígenas não correspondiam aos valores da modernidade. [...] E à escola cabia levar a cabo tal incumbência, através de programas de submersão cultural e linguística. (MAHER, 2006, p. 20)

Tal modelo de educação, entretanto, não se configurou, conforme se planejou, devido a sua ineficiência em ensinar as crianças indígenas uma segunda ou terceira língua, particularmente a língua portuguesa. Considerando que as crianças indígenas em dado momento de suas vidas passam pela educação indígena, quando aprendem e vivenciam cotidianamente os seus hábitos e costumes, sejam eles linguísticos, místicos, entre outros, visto que:

Nas sociedades indígenas, o ensinar e o aprender são ações mescladas, incorporadas à rotina do dia a dia, ao trabalho e ao lazer e não estão restritas a nenhum espaço específico. A escola é todo o espaço físico da comunidade. Ensina-se a pescar no rio, evidentemente. Ensina-se a plantar no roçado. Para aprender, para ensinar, qualquer lugar, é lugar, qualquer hora é hora... [...] $\mathrm{E}$, além disso, o ensino não é uma responsabilidade de uma única pessoa, ele é responsabilidade de todos. Na educação Indígena, não existe a Figura do "professor". São vários os "professores" da criança. A mãe ensina; ela é professora. O pai é professor, o velho é professor, o tio é professor, o irmão mais velho é professor. Todo mundo é professor... e todo mundo é aluno. (MAHER, 2006, p. 17-18) 
Assim, os vários segmentos não indígenas responsáveis pela educação escolar reconhecem que seria impossível a continuidade dos processos de ensino e aprendizagem sem a participação dos indígenas no espaço da sala de aula. Igualmente, sentem a necessidade de formar os indígenas para atuarem como professores. Entretanto, somente a partir da década de 1970 surgem os primeiros programas de formação de professores indígenas.

Contudo, há de se destacar que a participação do indígena professor se restringia apenas às classes ou séries de alfabetização, em que os mesmos ensinavam apenas a língua materna. Mas, com o passar dos anos e de atuação do indígena nos processos de aprendizagem das crianças, as comunidades começam a se articular em prol de um novo cenário educacional.

Dessa forma, inicia-se com a participação das comunidades indígenas a criação de várias escolas em terras indígenas, com o objetivo de aquisição de conhecimentos também da sociedade não indígena, com atenção especial ao ensino da língua portuguesa, domínio das operações matemáticas, para aprender a lidar com o dinheiro e, entre outros, "para que pudessem estabelecer relações menos submissas e mais igualitárias tanto com setores do indigenismo oficial, quanto com outros segmentos de sociedade brasileira" (GRUPIONI, 2006, p. 47).

Nesta perspectiva, têm-se as políticas públicas para a formação do indígena professor, inicialmente em curso de nível médio - Magistério Indígena e posteriormente a este, em nível superior - o Curso de Licenciatura Intercultural, sendo esta não só uma demanda emergente dos professores, mas sim, uma necessidade de capacitar o indígena para atuar na docência, pois:

A formação de índios como professores e gestores das escolas localizadas em terras indígenas é hoje um dos principais desafios e prioridades para a consolidação de uma Educação Escolar Indígena pautada pelos princípios da diferença, da especificidade, do bilinguismo e da interculturalidade. [...] Pode-se dizer que esta é uma tarefa complexa, que tem encontrado soluções muito diferentes em várias localidades do país, e para a qual não há um único modelo a ser adotado, vista a extrema heterogeneidade e diversidade de situações sociolinguísticas, 
culturais, históricas e de formação e escolarização vividas pelos professores índios e por suas comunidades. (GRUPIONI, 2006, p. 51)

A esse processo de formação do indígena professor, Grupioni (2006) sugere que esse professor indígena deva ser formado também como pesquisador, não só de aspectos relevantes da história e da cultura do seu povo, mas também de outros conhecimentos significativos nas diversas áreas de conhecimento.

Neste contexto, compartilharemos as trajetórias pessoais e profissionais dos indígenas professores dos estados do Tocantins e do Amazonas no decorrer de seus processos de formação a que estamos atuando como formadores na área do ensino de Matemática desde os anos de 2006 aos dias atuais. Analisaremos as falas em conjunto dos professores que se deram por meio de narrativas orais e entrevistas narrativas ocorridas no momento de apresentação entre os pares. Outras falas foram advindas das entrevistas narrativas que ocorreram em diferentes momentos do processo de formação, tendo ou não um cenário propício para a recolhimento das informações.

Para Jovchelovitch; Bauer (2008, p. 91), “comunidades, grupos sociais e subculturas contam histórias com palavras e sentidos que são específicos à sua experiência e ao seu modo de vida”. Assim, ressaltamos a riqueza das informações recolhidas que se constituíram em uma teia de informação e conhecimento sobre a vida tanto pessoal como profissional do ser indígena professor, tendo como foco de discussão inicial seus lócus de ensino e de vivência cotidiana.

Vislumbrar conhecer o outro em suas singularidades nos faz aguçar os nossos sentidos para ouvir, compreender, entender e aceitar o outro, fato que também nos conduz a falar sobre nós, gerando assim um compartilhar de sentimentos e de diferentes histórias que em certos pontos convergem, quando se trata da trajetória de formação do ser professor, ou seja, desvelando nas nuances entre o pesquisador e os pesquisados. Como nos indicam:

Inevitavelmente, pesquisadores narrativos experimentam esta tensão, pois a pesquisa narrativa é relacional. Eles devem tornar-se completamente envolvidos, devem "apaixonar-se" por seus participantes, e devem também dar um passo atrás e olhar suas próprias 
histórias na pesquisa, as histórias dos participantes, assim como a mais ampla paisagem a qual todos eles vivenciam. [...] Estas são uma mistura de "você e eu", do participante e do pesquisador - são notas sobre o que você fez, sobre com você, sobre o que estava ao nosso redor, sobre o lugar onde estávamos, sobre os sentimentos, sobre eventos correntes e sobre lembranças de fatos passados. (CLANDININ; CONNELLY 2011, p. 121 -122)

Nesse sentido, procuraremos entender as histórias de vidas do ser indígena professor ao escrever sobre a importância das pesquisas com biografias e histórias de vida de professores, entre outras histórias que conduzem as reflexões e compreensões, a dizer que:

\begin{abstract}
Entendendo o "ser professor" como uma experiência necessariamente compartilhada, baseada no encontro com os outros, as trajetórias e as histórias de vida ganham relevo por oferecerem pistas sobre como se constituiu a profissão docente, assim como sobre os limites da intervenção do professor. Seus interesses, motivações e experiência são elementos cruciais para desvelar um elemento tão negligenciado nos estudos sobre o tema, aquele da dimensão humana do professor. (OLIVEIRA; FILHO, 2011 p. 117)
\end{abstract}

Nessa perspectiva de conhecer a realidade formativa dos professores indígenas que os indagamos sobre as suas experiências profissionais, ou seja, os primeiros passos dados em direção as suas atuações em sala de aula. E se suas experiências se constituíram no individual ou no coletivo. Como se dá a atuação em sala de aula, considerando a vida pessoal, social e cultural, ponderando que alguns casos o pertencimento sociocultural tenha favorecido o trilhar da caminhada para tornarem-se professores e constituírem-se na profissão de professor.

Assim sendo, acreditamos que esses elementos contribuíram para nossa “impregnação", como pesquisadores, com os sujeitos da pesquisa, pois permitiram uma aproximação com o pensamento e os sentimentos vivenciados por esses sujeitos no seu processo de formação a partir de suas histórias de vida como professores indígenas, nas quais "se estabelece a relação de colaboração, na qual tanto o investigador quanto os sujeitos participantes têm VOZ" (ARAGÃO, 2011, p. 22), 
Em vários momentos, detectamos no recolhimento das informações tanto nas falas, como nos escritos desses professores, certos sentimentos: tristeza, dor, satisfação, alegria ao narrar suas histórias, lembranças e memórias de um tempo em que a rigidez, a falta de diálogo imperava fortemente entre os formadores e os indígenas. Assim as condensamos:

Em um primeiro momento de nossa atuação como professores em sala de aula, não desenvolvíamos atividades de ensino e, sim de manter a ordem e a disciplina dos estudantes no decorrer das aulas que eram ministradas pelos professores não indígenas. Tal atuação se fez necessária devido a esses professores não falarem as línguas indígenas e as crianças se encontravam em processos de aquisição da língua portuguesa. [...] com o passar dos anos, os distintos segmentos educativos que atuavam nas comunidades indígenas notam que era quase impossível instituir os processos de ensino e aprendizagem sem a participação do indígena nesse processo. Dá-se início à escolarização dos indígenas, tanto em língua portuguesa, como na escrita desta. Surgem então os primeiros professores indígenas, que atuavam juntamente com o professor não indígena nas classes alfabetizadoras. [...] Considerando as nossas diferenças culturais e que estas sempre se fizeram presentes em todos os espaços da aldeia e também na escola marcada pela presença do ancião e de outras lideranças, que estavam a questionar o ensino e as formas com que os professores faziam acontecer as aulas. Com isso, os órgãos governamentais e não governamentais começam a discutir a formação do indígena professor. Em um primeiro estágio, o Curso de Magistério Indígena. Com o avanço no nível de escolaridade dos estudantes, surgem novas reivindicações de formação e capacitação dos professores indígenas. Fomentando os primeiros Cursos de Licenciaturas específicas para os professores indígenas. Vale destacar que durantes todos esses processos de formação, nós, professores sofremos muito, pois tivemos que deixar nossas aldeias, casas, famílias para irmos estudar. Dos professores formadores vales ressaltar que eram poucos que conheciam a realidade indígena. [...] havia uma incompreensão entre as diferentes culturas indígenas em formação e os professores formadores, fato que levou muitos indígenas a desistirem. [...] em dias atuais sentimos a necessidade de estudar, nos capacitar e termos um curso superior para melhor atuarmos nas escolas de nossas comunidades. Os avanços já são notados com relação a nossa formação, para além de nossa atuação como professores formados. Temos hoje parentes ocupando cargos de importância em nossas escolas (diretores escolares, coordenadores pedagógicos e financeiros), em nosso Estado (Diretorias Regionais de Ensino e Secretarias Estaduais e Municipais de Educação) e em nosso país (cargo de administração no Ministério da Educação). 


\section{Considerações Finais}

Quanto aos anseios dos povos indígenas podemos destacar que nas escolas de suas comunidades, os processos de ensino e aprendizagem devem considerar e respeitar, no sentido de que, o conhecimento a ser construído nesses espaços deve ir além dos conhecimentos próprios da cultura do seu mundo, não com o intuito de substituí-los, mas de usá-los como um processo que permita a cada estudante sentir-se parte integrante dele.

Assim, a formação do professor indígena não pode ocorrer de forma dissociada da realidade do seu povo, da sua comunidade, e sim realizada de modo a articular a integração da educação formal por meio da Matemática, da História, da Geografia, e demais áreas do conhecimento, com a educação indígena, a qual se funda nas tradições de cada povo e se manifesta nos rituais, nas festas, nas construções de casas, de barcos, de utensílios de caça e pesca, na confecção de cestaria e de comida, da agricultura, além da leitura da natureza e do céu. Atividades estas que podem ser o mote para uma educação escolar mais significativa.

Neste sentido, entendemos ser necessário pensar em processos de formação para professores indígenas a partir da sua realidade, necessidades e de seus pertencimentos. Uma formação pautada no respeita às suas crenças, seus valores e mitos, que reconheça as autoridades de cada etnia, que evidencie, quando possível, a relação entre os saberes tradicionais e os conhecimentos formais da Matemática e das distintas áreas do conhecimento, para que assim, o professor possa adquirir uma base conceitual que lhe permita fazer um ensino de Matemática de forma mobilizada com significado aos seus estudantes.

\section{Referências}

ARAGÃO, Rosália Maria Ribeiro de. Memórias de formação e docência: bases para a pesquisa narrativa. In: CHAVES, Sílvia Nogueira; BRITO, Maria dos Remédios de. Formação e docência: perspectivas da pesquisa narrativa e autobiográfica. Belém: CEJUP, 2011. 
CONNELLY, F. Michael; CLANDININ, D. Jean. Relatos de experiência e investigación narrativa. In: LARROSA, Jorge. Déjame que te cuente: ensayos sobre narrativa y educación. Buenos Aires: Laertes, 1995.

CLANDININ, D. Jean; CONNELLY, F. Michael. Pesquisa narrativa: experiência e história em pesquisa qualitativa. Tradução: Grupo de pesquisa narrativa e Educação de professores ILEEL/UFU. Uberlândia: EDUFU, 2011.

D'AMBROSIO, Ubiratan. Etnomatemática: elo entre as tradições e a modernidade. 2. ed. Belo Horizonte: Autêntica, 2002 (Coleção Tendências em Educação Matemática).

D'AMBROSIO, Ubiratan. Etnomatemática e educação. In: KNIJNIK, Gelsa; WANDERER, Fernanda; OLIVEIRA, Cláudio José (Orgs.). Etnomatemática, currículo e formação de professores. Santa Cruz do Sul: EDUNISC, 2004.

GERDES, PAULUS. Etnomatemática: reflexões sobre matemática e diversidade cultural. Ribeirão: 2007.

GONÇALVES, Terezinha Valim Oliver. A pesquisa narrativa e a formação de professores: reflexões sobre uma prática formadora. In: CHAVES, Sílvia Nogueira; BRITO, Maria dos Remédios de. Formação e docência: perspectivas da pesquisa narrativa e autobiográfica. Belém: CEJUP, 2011.

GRUPIONI, Luís Donisete Benzi. Contextualizando o campo da formação de professores indígenas no Brasil. In: GRUPIONI. Luís Donisete Benzi (Org.). Formação de professores indígenas: repensando trajetórias. Brasília, 2006. (Coleção Educação para todos).

JOVCHELOVITCH, Sandra; BAUER, Martin W. Entrevista narrativa. In: BAUER, Martin W.; Gaskell, George. Pesquisa qualitativa com texto, imagem e som: manual prático. 7. ed. Petrópolis: Vozes, 2008.

MAHER, Terezinha Maher. Formação de Professores Indígenas: uma discussão introdutória. In: GRUPIONI. Luís Donisete Benzi. (Org.). Formação de professores indígenas: repensando trajetórias. Brasília, 2006. (Coleção Educação para todos).

MENDES, Jaqueline Rodrigues. Etnomatemática: uma proposta de ensino de matemática entre os Guarani da barragem. In: SEKI, Lucy (Org.). Linguística Indígena e educação na América Latina. Campinas: UNICAMP, 1993.

OLIVEIRA, Marcus Aurélio Taborda de; FILHO, Luciano Mendes de Farias. Antonio de Vinão Frago: a crítica da educação como crítica cultural. In: REGO, Teresa Cristina. et al. (Org.). Memória, história e escolarização. Petrópolis: Vozes, 2011 (Coleção pedagogia contemporânea).

PAULA, Eunice Dias de. A interculturalidade no cotidiano de uma escola indígena. Cadernos Cedes, v. 49, p. 76-91, 1999. 
PINTO, Fabiana de Freitas. Licenciatura específica para formação de professores indígenas/turma Mura: um balanço dos dois primeiros anos do Curso à luz das expectativas dos alunos. 2011, 140 f. Dissertação (Mestrado em Educação) - Universidade Federal do Amazonas, Mestrado em Educação, Manaus, 2011.

SCANDIUZZI, Pedro Paulo. Educação indígena $x$ educação escolar indígena: uma relação etnocida em pesquisa etnomatemática. São Paulo: Editora UNESP, 2009.

SILVA, Aglair Gomes da. et al. Aldeias Indígenas Mura. Manaus: Editora da Universidade Federal do Amazonas, 2008.

SILVA, Rosa Helena Dias da. Afinal quem educa os educadores indígenas? In: GOMES, Nilma Lino; SILVA, Petronila Beatriz Gonçalves e (Orgs.). Experiências étnico-culturais para a formação de professores. Belo Horizonte: Autêntica, 2002 (Coleção Trajetória)

SILVA, Rosa Helena Dias da; HORTA, José Silvério Baia. Licenciaturas específicas para formação de professores indígenas nas instituições de ensino superior públicas da Amazônia brasileira participação e protagonismo compartilhado. Revista Currículo sem Fronteiras, v.10, n.1, p.182-194, jan./jun., 2010. Disponível em:

<http://www.curriculosemfronteiras.org/index.htm>. Acesso: 01-09-2014.

STUANI, Geovana Mulinari. A construção curricular crítica no ensino de ciências naturais e suas implicações na prática docente. 2010, 194 f. Dissertação (Mestrado em Educação Científica e Tecnológica) - Universidade Federal de Santa Catarina, Mestrado em Educação Científica e Tecnológica, Florianópolis, 2010.

SEMINÁRIO DESAFIOS PARA UMA EDUCAÇÃO SUPERIOR PARA OS POVOS INDÍGENAS NO BRASIL. POLÍTICAS PÚBLICAS DE AÇÃO AFIRMATIVA E DIREITOS CULTURAIS DIFERENCIADOS. 30 a 31 de agosto de 2004, Brasília. Relatórios de Mesas e Grupos.

Brasília: TRILHAS DE CONHECIMENTOS; LABORATÓRIO DE PESQUISAS EM ETNICIDADE, CULTURA E DESENVOLVIMENTO - LACED; MUSEU NACIONAL/UNIVERSIDADE FEDERAL DO RIO DE JANEIRO 2004. Disponível em:

<http://www.observa.ifcs.ufrj.br/relatorios/desafiosES_indigenas.pdf >. Acesso em 01-092015. 